\title{
Role of HLA DRB1*15 and HLA DRB1*16 alleles in the genetic susceptibility to develop systemic lupus erythematosus (SLE) after Chikungunya and Zika viruses infection in México
}

Sepúlveda-Delgado $\mathrm{J}^{1}$, Danis-Lozano $\mathrm{R}^{2}$, Ocaña-Sibilla $\mathrm{MJ}^{1}$, Ramirez-Valdespino JC${ }^{1}$, Cetina-Díaz $\mathrm{JH}^{1}$, Bulos-Rodriguez $\mathrm{P}^{1}$, Hernández-Doño $\mathrm{S}^{3}$, Ruiz-Gómez $\mathrm{D}^{3}$, García $\mathrm{R}^{3}$, Juárez-Nicolás $\mathrm{F}^{3}$, TeveraGamboa $\mathrm{MG}^{4}$, Vera-Lastra OL ${ }^{5}$, Jara Lj5, Canseco-Avila LM ${ }^{1}$, Dominguez-Arrevillaga $\mathrm{S}^{1}$, TrujilloMurillo $\mathrm{K}^{1}$, Julio Granados $\mathrm{J}^{3^{*}}$

\author{
${ }^{1}$ Hospital Regional de Alta Especialidad Ciudad Salud, Tapachula, Chiapas, M éxico; \\ ${ }^{2}$ Regional Center of Public Health Research of National Institute of Public Health, Tapachula, Chiapas, Mexico; \\ ${ }^{3}$ Department of Transplants and Immunogenetics, Instituto Nacional de Ciencias M édicas y Nutrici ón Salvador Zubir án, Ciudad \\ de México, Mexico; \\ ${ }^{4}$ Hematology Department, Hospital General de Zona \#1 IMSS, Tapachula, Chiapas, M éico; \\ ${ }^{5}$ Hospital de Especialidades Dr. Antonio Fraga Mouret, Centro M édico a Raza, CDMX,M éico.
}

\begin{abstract}
Systemic lupus erythematosus (SLE) is a clinically and genetically heterogeneous disease particularly prevalent in Mexico. Althoughits etiology is unknown, genetic factors strongly influence its presenceas well as triggering factors, such as viral infections, including Cytomegalovirus and Epstein-Barr virus. Here,the study presents the appearance of de novoSLE (patients who did not present SLE before de virus infection, corroborated by serological analysis and negative for antinuclear antibodies) cases in Mexicans who live near the southern border of Mexico, who presented clinical symptoms of arthritic, hematological, mucocutaneous and renal SLE, after Zika and/ or Chikungunya virus infection. Low resolution class II HLA typing was performed, which found a significantly increased frequency of HLA DRB $1 * 02$ (15 and 16)when compared to a group of 99 healthy individuals $(P=0.001$, $\mathrm{OR}=4.5$, IC95\% 1.8 11.0). All the patients were diagnosed with SLE 1 to 3 years after being confirmed with the Zika, and/or Chikungunya infection. At the point of acute viral infection, none of the patients presented clinical signs or symptoms of autoimmunity or were negative for antinuclear antibodies. In genetically susceptible individuals, Zika and Chikungunya viral infection can trigger SLE.
\end{abstract}

Keywords: systemic lupus erythematosus, HLA antigens, Chikungunya virus, Zika virus, genetic susceptibility

\section{INTRODUCTION}

Systemic lupus erythematosus (SLE) is an autoimmune systemic disorder particularly prevalent in

*Correspondence to: Dr. Julio Granados, PhD., Department of Transplants and Immunogenetics, Instituto Nacional de Ciencias Médicas y Nutrición Salvador Zubirán, 7a Cerrada de Fray Pedro de Gante
Mexico with multiple clinical manifestations, in which tissue and cellular damage is mediated by autoantibodies and immune complexes ${ }^{[1-4]}$. Global incidence has been reported as between 1 to 10 per 100,000 per-

50, Tlalpan Sección XVI, CDMX, México. C.P 14080.Tel: 005255 54850080,E-mail: julgrate@yahoo.com.

Conflict of interests: The authors declared no conflict of interests. 
son-year, while its prevalence is calculated between $20 \sim 70$ cases per 100,000 person, with regional variations around the world ${ }^{[5]}$. The pathogenic mechanisms of SLE includes genetic and environmental factors, of which Class II main histocompatibility complex (MHC) gene polymorphisms show increased consistent genetic susceptibility in certain populations and have been strongly associated with SLE and its phenotypes, mainly HLA-DR3 and HLA-DQ2 ${ }^{[6-8]}$. In addition, viral infections have been shown to be highly associated with the onset and/or exacerbations of SLE, including Epstein-Barr virus, parvovirus B19 retrovirus and cytomegalovirus ${ }^{[9]}$. The role of other viruses such as Zika, Chikungunya and Dengue arbov iruses has not been clearly established, but their role could take more relevance specially in geographical areas where there is anactive transmission of these viruses. The reference medical center, Hospital Regional de Alta Especialidad Ciudad Salud, located in Tapachula, near the south border of México and Guatemala where the transmission of Zika and Chikungunya viruses began in 2014, paid close attention to autoimmune rheumatic diseases through its outpatient. During 2016 and 2017 , we recorded an increase in the number of cases of SLE compared to previous years, in a situation that coincided with the outbreak of Zika and Chikungunya.Therefore, the study performed a retrospective case-control study to evaluate the association of Class II MHC genes with the presence of SLE in subjects with previously confirmed Zika and/or Chikungunya infections.

\section{MATERIALS AND METHODS}

\section{Patients}

Patients with de novo SLE diagnosed between 2015 and 2017, with a background of previously confirmed Zika or Chikungunya infection (by qRT-PCR and serology) during the active transmission of those arbovirus in Tapachula, Chiapas, were enrolled. The information was gathered from clinical records concerning their arboviral infection including, the time elapsed between the confirmed infection and onset of SLE symptoms, the SLE-onset related symptoms, the SLEDAI at diagnosis, and the autoantibodies profile at SLE diagnosis ${ }^{[10]}$.

\section{Autoantibody profile}

In order to establish whether SLE related antibodies found in each subject enrolled were present at the moment of arboviral infection, the study determined autoantibody profiles by immunoenzymatic assay (Euroline ANA profile 3, Euroimmun ${ }^{\circledR}$ ) from stored sera collected to perform molecular diagnoses during the outbreak ${ }^{[11]}$.

\section{HLA typing}

To evaluate genetic SLE susceptibility, low resolution HLA typing was performed by Sequence Specific Primers (SSP, TBG technologies) for HLA DRB1 and DQB1 after PCR amplification; allele and haplotype frequencies were determined and compared with the group of 99 healthy individuals (198 alleles) ${ }^{[12]}$.

\section{Statistical Analysis}

The study performed non-parametric statistics (Chi Squared test and Fisher exact test) by using the Epi Info program (version 10.0) and the StatCalc Subprogram based on two by two tables. $P<0.05$ was set of standards statistical significance.

\section{RESULTS}

\section{Patients}

Between 2015 and 2017, 21 new cases of SLE was registered in the autoimmunity clinic. Of those, 16 patients had a demonstrated arboviral infection. All subjects corresponded to female; averageage at onset of SLE 25.5 years (17 60); all cases were referred 1 to 3 years due to having persistent symptoms such as fever, asthenia, cutaneous manifestations, arthralgias and/or arthritis, anemia and/or leukopenia and hematuria, proteinuria or active urine sediment.

\section{Diagnostic approach}

In all cases,the diagnostic approach corresponded to a suspicion of SLE due to the clinical picture. All subjects were tested for antinuclear antibodies by indirect immunofluorescent test and specific antibodies by ELISA and Western blot analysis (Euroimmune ${ }^{\circledR}$ ). SLE was confirmed based on 2012 SLICC/ACR classification criteria ${ }^{[13]}$. Treatment was started according organic damage. The main characteristics of the subjects, including treatment and outcome, were shown in Table1.

\section{Clinical outcome after virus infections}

The mean time elapsed between arboviral infection and SLE-onset signs and symptoms was (1.80 \pm 0.68$)$ years. The common SLE-related signs and symptoms were arthritis in 8 cases (50\%), lymphopenia in 7 cases $(43.7 \%)$, proteinuria in 5 cases $(31.2 \%)$, mucocutaneous manifestations in 6 cases $(37.5 \%)$, and neuropathy in 2 cases $(12.5 \%)$. The evolution time of SLE-related signs and symptoms before confir- 
mation of diagnosis was $(3.30 \pm 1.14)$ months. SLEDAI at diagnosis was $12.50 \pm 4.89$, and the common phenotypes were: hematologic in 8 cases $(50 \%)$, articular in 8 cases $(50 \%)$, renal in 5 cases $(31.2 \%)$, mucocutaneous in 3 cases $(18.7 \%)$, and neurologic in 2 cases. The main data of each case was shown in Table 1.

\section{HLA gene frequencies}

Table 2 showed gene frequencies HLA DRBl alleles and 16 SLE patients' (32 alleles) from Tapachula, Chiapas and for comparison, it also showed the group of 99 ethnically matched healthy controls (198 alleles). As it is readily seen that HLA DRB $1 * 04$ was the most common allele in patients and controls, confirming that the ethnicity background in patients and healthy controls was the same. Interestingly, there was a significantly increased frequency in HLA DRB1*15 in patients as compared to controls $(P=0.05, \mathrm{OR}=2.6$, 95\% CI:1.2 5.4), likewise, HLA DRB1*16 also increased in the patient group as compared to the controls $(P=0.03, \mathrm{OR}=3.5,95 \% \mathrm{CI}: 1.6 \sim 7.9)$. The gene frequencies of the remaining alleles in the patient groups were similar to those present in the control group.

Table 1 Gene frequencies HLA-DRB1 in SLE patients from Tapachula Chiapas

\begin{tabular}{|c|c|c|c|c|c|c|c|}
\hline \multirow{2}{*}{ Alleles } & \multicolumn{2}{|c|}{ Patients $(N=32)$} & \multicolumn{2}{|c|}{ Control( $N=198)$} & \multirow{2}{*}{$P$ value } & \multirow{2}{*}{ OR } & \multirow{2}{*}{$95 \% \mathrm{CI}$} \\
\hline & $n$ & gf & $n$ & gf & & & \\
\hline DRB1*04 & 9 & 0.281 & 47 & 0.237 & 0.75 & 1.2 & $0.6 \sim 2.5$ \\
\hline DRB $1 * 15$ & 6 & 0.188 & 13 & 0.066 & 0.05 & 2.6 & $1.2 \sim 5.4$ \\
\hline $\mathrm{DRB} 1 * 08$ & 5 & 0.156 & 33 & 0.167 & 0.9 & 0.9 & $0.4 \sim 2.3$ \\
\hline $\mathrm{DRB} 1 * 16$ & 4 & 0.125 & 5 & 0.025 & 0.03 & 3.5 & $1.6 \sim 7.9$ \\
\hline $\mathrm{DRB} 1 * 03$ & 2 & 0.063 & 11 & 0.056 & 1 & 1.1 & $0.2 \sim 5.4$ \\
\hline DRB1*14 & 2 & 0.063 & 21 & 0.106 & 0.7 & 0.6 & $0.1 \sim 2.5$ \\
\hline $\mathrm{DRB} 1 * 10$ & 2 & 0.063 & 3 & 0.015 & 0.3 & 4.3 & $0.7 \sim 27.0$ \\
\hline DRB1*11 & 1 & 0.031 & 20 & 0.101 & 0.3 & 0.3 & $0.04 \sim 2.2$ \\
\hline $\mathrm{DRB} 1 * 01$ & 1 & 0.031 & 10 & 0.051 & 0.98 & 0.6 & $0.1 \sim 4.9$ \\
\hline
\end{tabular}

Table 2 Gene frequencies HLA-DQB1 in SLE patients from Tapachula Chiapas

\begin{tabular}{|c|c|c|c|c|c|c|c|}
\hline \multirow{2}{*}{ Alleles } & \multicolumn{2}{|c|}{ Patients $(N=32)$} & \multicolumn{2}{|c|}{ Control $(N=198)$} & \multirow{2}{*}{$P$ value } & \multirow{2}{*}{ OR } & \multirow{2}{*}{$95 \% \mathrm{CI}$} \\
\hline & $n$ & gf & $n$ & gf & & & \\
\hline DQB1*03 & 14 & 0.438 & 92 & 0.465 & 0.9 & 0.9 & $0.4 \sim 1.9$ \\
\hline DQB1*05 & 7 & 0.219 & 12 & 0.061 & 0.008 & 3.1 & $1.6 \sim 6.2$ \\
\hline DQB1*04 & 5 & 0.156 & 33 & 0.167 & 0.9 & 0.9 & $0.4 \sim 2.3$ \\
\hline DQB1*06 & 5 & 0.156 & 15 & 0.076 & 0.2 & 2.3 & $0.8 \sim 6.7$ \\
\hline $\mathrm{DQB} 1 * 02$ & 1 & 0.031 & 33 & 0.167 & 0.08 & 0.2 & $0.02 \sim 1.2$ \\
\hline
\end{tabular}

Since HLA DRB1*15 and HLA DRB1*16 are subspecificities of HLA DRBI*02, the study also analyzed the frequency of HLA DRB1*02 in patients and controls and found an even stronger statistical significance $(P=0.001, \mathrm{OR}=4.5,95 \% \mathrm{CI}$ : $1.8-11.0)$.

It is clear HLA DQB $1 * 03$ is the most frequent allele in patients and controls $(P>0.05)$ and it is also true for the Mexican population (mestizo and indigenous). The HLA DQB1*05 was found to be significantly increased in the patient group when compared to controls $(P=0.008, \mathrm{OR}=3.1,95 \% \mathrm{CI}$ : 1.6 6.2). The remaining alleles were equally distributed in patients and controls.

\section{DISCUSSION}

This paper reported the genetic susceptibility for developing SLE after being infected with the Chikungunya and/or Zika virus in an endemic region in the south border of Mexico next to Central America.

The study reported the relevance of HLA DRB $1 * 15$ and HLA DRB1*16 as risk factors for SLE. It is important to note that gene frequencies of these two alleles are prevalent in oriental populations and in indigenous individuals from Mexico ${ }^{[14]}$. The relationship between Orientals and the Amerindian populations dated back to ancient individuals that populated America around thirty thousand years ago. However,it is important to note that SLE patients from the southern border differ from SLE patients in urban cities. Their genetic admixture was strongly influenced by Caucasian (white European) individuals where HLA DRBI*03 was the relevant allele ${ }^{[15-16]}$. This suggests that the mechanism of SLE autoimmunity after Chikungunya infection might trigger a different genetic pathway when compared to those positive for HLA DRB $1 * 03$.

In conclusion, this paper suggests that the viral infections, particularly in endemic regions including Zika and Chikungunya viruses, trigger the development of autoimmunity (SLE) in genetically susceptible individuals. HLA typing is a useful marker for 
detecting genetic susceptibility in endemic regions with viral infections. Therefore, this paper suggests that HLA typing will also be useful in determining prognosis and individualized treatment.

\section{Acknowledgements and funding}

This project was supported by CONACyT SALUD-S0008-2016-01-273175.

\section{References}

[1] Mak A, Cheung MW, Chiew HJ, et al. Global trend of survival and damage of systemic lupus erythematosus: meta-analysis and meta-regression of observational studies from the 1950 s to $2000 \mathrm{~s}[\mathrm{~J}]$. Semin Arthritis Rheum, 2012,4 41(6):830-839.

[2] Granados J, Zúñiga J, Acuña-Alonzo V, et al. Influencia de alelos y haplotipos del complejo principal de histocompatibilidad en la susceptibilidad a lupus eritematoso generalizado en la población mexicana[J]. Gac Med Mex, 2006,142:195-199

[3] Tsokos GC, Lo MS, Reis, Sullivan PC, et al. New insights into the immunopathogenesis of systemic lupus erythematosus[J]. Nat Rev Rheumatol, 2016,12: 716-730

[4] Guillermo J, Pons-Estel MD, Graciela S, et al. Understanding the epidemiology and progression of systemic lupus erythematosus[J]. Semin Arthritis Rheum, 2010,39(4):1-23

[5] Carter EE, Barr SG, Clarke AE. The global burden of SLE: prevalence, health disparities and socioeconomic impact[J]. Nat Rev Rheumatol, 2016,12(10):605-620

[6] Barturen G, Alarcón-Riquelme ME. Systemic lupus erythematosus in 2016: Gene expression profiling comes closer to the clinic[J]. Nat Rev Rheumatol, 201,13(2):69-70.

[7] Ceccarelli F, Perricone C, Borgiani P, et al. Genetic factors in systemic lupus erythematosus: contribution to disease phenotype[J]. J Immunol Res,2015,2015:745647

[8] Matveǐkov GP, Levin VI, Dosin IM, et al. HLA antigens in systemic lupus erythematosus patients[J]. Ter
Arkh, 1984,56: 40-44

[9] Fujinami RS, Herrath MG, Christen U,et al. Molecular mimicry, bystander activation, or viral persistence: infections and autoimmune disease molecular mimicry, bystander activation, or viral persistence: infections and autoimmune disease[J]. Clin Microbiol Rev, 2006,19:80-94

[10] Bombardier C, Gladman DD, Urowitz MB, et al. Derivation of the SLEDAI. A disease activity index for lupus patients. The committee on prognosis studies in SLE[J]. Arthritis Rheum, 1992,35: 630-640

[11] Shoenfeld Y, Slor H, Shafrir S, et al. Diversity and pattern of inheritance of autoantibodies in families with multiple cases of systemic lupus erythematosus[J]. Ann Rheum Dis, 1992,51(5):611-618

[12] Fernández-Torres J, Flores-Jiménez D, Arroyo-Pérez A, et al. The ancestry of the HLA-DRB1*15 allele predisposes the Mexican mestizo to the development of aplastic anemia[J]. Hum Immunol, 2012,73: 840-843

[13] Gladman D, Ginzler E, Goldsmith C, et al. The development and initial validation of the Systemic Lupus International Collaborating Clinics/American College of Rheumatology damage index for systemic lupus erythematosus[J]. Arthritis Rheum,1996,39(3):363-369.

[14] Zúñiga J, Yu N, Barquera R, et al. HLA class I and class II conserved extended haplotypes and their fragments or blocks in Mexicans: implications for the study of genetic diversity in admixed populations[J]. PLoS One,2013,8(9):e74442

[14] Bekker-Mendez C, Yamamoto-Furusho JK, VargasAlarcón G, et al. Haplotype distribution of class II MHC genes in Mexican patients with systemic lupus erythematosus[J]. Scand J Rheumatol,1998,27(5):373-376

[16] Deng Y, Tsao BP. Genetic susceptibility to systemic lupus erythematosus in the genomic era[J]. Nat Rev Rheumatol,2010,6(12):683-692

(Received 17 August 2018, Revised 08 October 2018, Accepted 17 October 2018) 